\title{
Peertechz
}

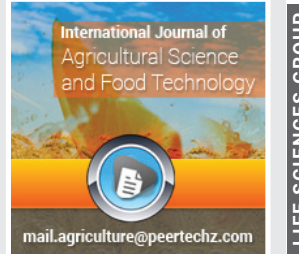

\section{Evaluating Drought tolerance indices for selection of drought tolerant Orange Fleshed Sweet Potato (OFSP) genotypes in Ethiopia}

Received: 30 July, 2021

Accepted: 20 August, 2021

Published: 24 August, 2021

*Corresponding author: Selamawit Abebe Gitore, Department of Dry Land Agriculture and Enterprise Development, Kenyatta University, School of Agricultural Science and Technology, Nairobi, Kenya, Tel: +254702601280; E-mail: abate4fam@gmail.com

Keywords: Genotypes; Drought tolerance indices; Coefficient of correlation; Sweet potato; Drought

https://www.peertechzpublications.com

Check for updates

\section{Selamawit Abebe Gitore ${ }^{1 *}$, Benjamin Danga ${ }^{2}$, Sylvia Henga ${ }^{1}$ and Fekadu Gurmu ${ }^{3}$}

'Department of Dry Land Agriculture and Enterprise Development, Kenyatta University,

School of Agricultural Science and Technology, Nairobi, Kenya

${ }^{2}$ Department of Agricultural Resource management, Kenyatta University, Kenya

${ }^{3}$ Southern Agricultural Research Center, Hawassa, Ethiopia

\begin{abstract}
The purposes of this study were to assess the effectiveness of drought tolerance indices for selection of drought tolerance in orange fleshed sweet potato genotypes. In order to assess efficiency of drought tolerance indices, 10 Orange Fleshed Sweet Potato genotypes (OFSP) were evaluated under Normal or full irrigation and extreme water stress environments. A total of 9 drought tolerance indices including Stress tolerance index (STI), Tolerance (TOL), Mean Productivity (MP), Geometric Mean Productivity (GMP), Stress Susceptibility Index (SSI) Yield Index (YI), Yield Stability Index (YSI), Harmonic Mean (HM), and Stress Intensity Index (SII) were calculated based on yield obtained from the two moisture regimes. Rank mean, standard deviation of ranks and rank sum were calculated to identify well-performed varieties according to all indices. These STI, GMP, YI, SII and TOL showed high and significant correlation under both (Yp) and (Ys) condition. In consideration of all indices a variety MUSG01406521-13, MUSG014065-21-14, and MUSG014019-7-50 exhibited the best mean of ranks and almost low standard deviation of rank. Among 10 genotypes, the combination of nine drought indices and deviation identified MUSG014065-21-13, MUSG014065-21-14, and MUSG014019-7-50 as a three promising and drought tolerant genotypes.
\end{abstract}

\section{Abbreviations}

STI: Stress Tolerance Index; TOL: Tolerance; MP: Mean Productivity; GMP: Geometric Mean Productivity; SSI: Stress Susceptibility Index; YI: Yield Index; YSI: Yield Stability Index; HM: Harmonic Mean; SII: Stress Intensity Index

\section{Introduction}

Water deficiency is one of the key abiotic factors affecting crop productivity. Water shortages for agriculture are becoming more common around the world. Drought adaptability in crops like sweet potato is therefore required. Breeding objectives should be pursued for the production of drought tolerant cultivars suitable for stress agriculture to overcome yield reduction under stress and highland environments. The combination of high yield stability and high relative yield under drought has been recommended as a viable selection criterion for assessing genotypic performance under varied degrees of water stress [1]. Genetic manipulation of the crop to improve tolerance is recommended among drought management options because of its sustainability and feasibility, especially in resource-poor areas [2,3]. The development of droughttolerant cultivars with acceptable agronomic and qualityrelated traits is largely dependent on the availability of genetic resources for tolerance, effective screening techniques, identification of genetic traits of tolerance [4], successful genetic manipulation of the desired genetic backgrounds, and finally the development of drought-tolerant cultivars with acceptable agronomic and quality-related traits [5]. The relative yield performance of genotypes in drought-stressed 
and non-stressed conditions can be utilized to discover drought-resistant cultivars in breeding programs for droughtprone areas $[6,7]$. Several drought indices based on genotype drought resistance or susceptibility have been proposed and calculated between yield under stress and optimal conditions in this regard. Indicators have been used to screen drought tolerant genotypes because they provide a measure of drought based on yield loss under drought conditions compared to normal conditions.

Drought indices have been used to screen drought-tolerant genotypes because they provide a measure of drought based on yield loss under drought conditions compared to normal conditions [8]. Different approaches have been employed by different studies to assess genetic differences in drought resistance. Drought resistance is defined as a genotype's relative yield compared to other genotypes treated to the same drought stress [9]. Drought susceptibility of a genotype is frequently assessed as a function of yield reduction under drought stress [10], although the results are muddled by genotype yield potential differences [11]. Several screening process for genotypes based on their performance in stress and non-stress contexts have been presented. According to [12], the Relative Drought Index (RDI) is a favorable indicator of stress tolerance. Lan (1988) proposed new drought resistance indicator (DI) indices that were widely accepted for identifying genotypes that produced good yield under stress and nonstress situations [13] defined stress tolerance (TOL) as the yield disparities between stressed and irrigated environments, and mean productivity (MP) as the average yield of genotypes under stress and non-stress circumstances. Breeders interested in relative performance frequently employ the Geometric Mean Productivity (GMP), because drought stress in field situations can fluctuate in intensity over time [14]. The Stress Susceptibility Index (SSI) was proposed by Fischer and Maurer [15] as a method of determining yield stability that took into account variations in both prospective and actual yields in a variety of settings. Clarke, et al. [16] employed SSI to assess drought tolerance in wheat genotypes and discovered year-toyear variance in SSI for genotypes, as well as the ability to rank their patterns. Guttieri et al. [17] used SSI to imply that an SSI $>1$ indicated above-average susceptibility to drought stress in spring wheat cultivars. The Yield Index (YI) proposed by [18] and the Yield Stability Index (YSI) proposed by Bouslamaand Schapaugh [19] were used to assess genotype stability under stress and non-stress situations. The Stress Tolerance Index (STI) was developed as a tool for identifying genotypes' high yield and stress tolerance potential [13].

The goal of this study was to determine the selection criteria for determining drought resistance in orange fleshed sweet potato varieties in Ethiopia so that acceptable cultivars could be selected for cultivation in Ethiopia's drought-prone areas.

\section{Materials and methods}

\section{Planting materials}

Ten orange fleshed sweet potato genotypes (OFSP) Wogabolige, MUSG014065-21-13, MUSG014065-21-14, Vita,
Napsot-12, CN1448-49-28-8, MUSG014019-7-22, Ukr/Eju-10, MUSG014019-7-50 and MUSG014001-3-11 already introduced from the CIP Kenya to Ethiopia and germplasm advanced from crossing experiment done by Hawassa Agricultural Research Center [20] in Ethiopia were used.

\section{Experimental design and procedures}

The experiment was carried out in Simple lattice design with two replications each for stress and non-stress condition in a field at Areka woreda Wolaita Zone, Ethiopia. The study site covers a portion of the zone located between 704'N37042'E, respectively. The yearly average max and min temperatuof the site are $15^{\circ} \mathrm{C}$ and $30^{\circ} \mathrm{C}$, respectively. Annual average $\mathrm{RF}$ is $1300 \mathrm{~mm}$ in the highland area and $600 \mathrm{~mm}$ or less in the low lands. Like the eastern part of Ethiopia, Wolaita zone is also highly affected by drought. Genotypes were arranged in 3 rows per plot with 5 plants per row using $30 \mathrm{~cm}$ spacing between plants and $90 \mathrm{~cm}$ row spacing, respectively. $30 \mathrm{~cm}$ length Vine tip cuttings were used as planting material and planted at depth of 4-6 cm.

\section{Data collected}

Drought tolerance indices: The storage root yield data were recorded for each genotype at both environment (nonstress and stress) and were subjected to calculate and analyze different drought selection indices using following formulas.

1) Stress susceptibility index (SSI) [15] SSI = (1- (Ys/Yp)/SII

2) Geometric mean $(\mathrm{GM}):[14] \mathrm{GM}=(\mathrm{Yp} * \mathrm{Ys})^{1 / 2}$

3) Tolerance (TOL): [13] TOL = (Yp-Ys $)$

4) Mean productivity index (MPI) [13] MPI $=(\mathrm{Ys}+\mathrm{Yp}) / 2$

5) Yield stability index(YSI): [18] $\mathrm{YSI}=\mathrm{Y}_{\mathrm{S}} / \mathrm{Y}_{\mathrm{P}}$

6) Harmonic mean productivity(HM): (Kristin et al., 1997) $H M=1 / 2\left(\left(1 / Y_{s}\right)+\left(1 / Y_{p}\right)\right.$

7) Stress tolerance index (STI): [14] STI = (Ys xYp)/Yp

8) Yield index [17] YI = (Ys/ Y̌s)

9) Stress intensity index (SII): [15] SII = 1- Ȳs/Ȳp

In the above formulas, Ys, Yp, $\bar{Y}$ s and $\bar{Y}$ p represent yield under stress, yield under non-stress for each genotype, yield mean in stress and non-stress conditions for all genotypes, respectively.

\section{Ranking of genotypes}

Different indices designate different genotypes as drought resistant; hence identifying drought tolerant genotypes based on a single criterion does not yield clear results. To identify desirable drought tolerant genotypes, the mean rank, standard deviation of ranks, and rank sum of all indices were calculated. For screening drought tolerant genotypes a rank sum (RS) was calculated by using the following relationship formula: 
Rank Sum (RS) = Rank Mean (R) + Standard Deviation of Rank (SDR) [21].

$\mathrm{SDR}=\left(\mathrm{S}^{2} \mathrm{i}\right)^{0.5}$

\section{Statistical analysis}

The mean storage root yield data were recorded for each genotype at both environment (non-stress and stress) and were subjected to calculate and analyze different drought selection indices using following using MS Excel. Rank mean, standard deviation of ranks and rank sum were calculated to identify well-performed varieties according to all indices. Correlation among indices and grain yield in two conditions were performed SPSS Version 20 software.

\section{Results}

\section{Comparing cultivars based on the resistance/tolerance indices}

Different drought tolerant indices were derived based on storage root yield of genotypes under non-stress (Yp) and stressed (Ys) environments (Table 1).

\section{Stress susceptibility index (SSI)}

The mean yield of genotypes under stress and nonstress conditions are Ys and Yp, respectively and genotypes with the lowest value (SSI 1) are more droughts tolerant. The results showed that all genotypes with the lowest SSI displayed drought resistance, such Vita (0.67), MUSG01406521-14 (0.67), Naspot-12 (0.69), MUSG014065-21-13 (0.71), MUSG014019-7-22 (0.74), Wogabolige (0.81), MUSG01405251-35 (0.81), CN1448-49-28-8 (0.81), MUSG014019-7-50 (0.84) and MUSG014001-3-11 (0.84).

\section{Tolerance (TOL)}

Low-valued genotypes (TOL) are more stable under two different environments and are suitable for drought tolerance screening of breeding materials. The lower TOL values were found in Genotypes MUSG014001-3-11(1.76) and CN144849-28-8 (2.7), whereas the higher TOL values were found in Genotypes MUSG014019-7-50 (6.7), MUSG014065-2113 (5.54), and Wogabolige (4.65), showing non suitable for drought conditions.

\section{Stress Tolerance Index (STI)}

Drought tolerance was indicated by genotypes with high Stress Tolerance Index (STI) values. High STI values indicate tolerance to moisture stress in the genotypes MUSG014065-2113 (0.71) and MUSG014065-21-14 (0.44). Low values indicate low tolerance to moisture stress, such as MUSG014001-3119 (0.03), CN1448-49-28-8 (0.08), Naspot-12 (0.22), and MUSG014052-51-35 (0.14).

\section{Yield Index (YI)}

Drought-tolerant genotypes with high Yield index (YI) values were discovered. Tolerance is defined as a genotype with a value greater than one, while susceptibility is defined as a genotype with a value less than one. As in the case of STI, the genotypes (MUSG014065-21-13) (1.86), (MUSG014065-21-14) (1.54), (Vita) (1.31), (Naspot-12) (1.04), and (MUSG014019-750) (1.00) have higher values. Cross-testing genotypes those are drought-resistant. YI levels were also found to be lower in genotypes that were susceptible to drought. (MUSG0140013-11) (0.26), (CN1448-49-28-8) (0.50), (MUSG014052-51-35) (0.66), (Wogabolige) (0.85), and (MUSG014019-7-22) all had lower e values (0.97).

\section{Yield Stability Index (YSI)}

Under stress and non-stress conditions, genotypes with high YSI values can be considered stable genotypes. The genotypes Vita (0.33), MUSG014065-21-14 (0.33), Naspot-12 (0.31), and MUSG014065-21-13 (0.30) had the greatest YSI values, indicating that they were stable under stress. Lower values indicated that they were un-stable under stress, and all other genotypes were intermediate.

\section{Mean Productivity Index (MPI)}

Under stress conditions, genotypes with a high value of this index are thought to be more desirable. Vita and MUSG014065-21-14 genotypes had a higher value and were considered tolerant, whilst

Table 1: Estimates of stress tolerance indices under full-irrigation and extreme water stress condition based on yield of ten orange fleshed sweet potato genotypes.

\begin{tabular}{|c|c|c|c|c|c|c|c|c|c|c|c|}
\hline Genotypes & Yp & Ys & STI & TOL & MPI & GMP & SSI & YI & YSI & HM & SII \\
\hline (Naspot-12)T39 & 4.35 & 1.35 & 0.22 & 3.0 & 1.22 & 2.42 & 0.44 & 1.04 & 0.31 & 2.06 & 0.69 \\
\hline (MUSG014001-3-11)T5 & 2.1 & 0.34 & 0.03 & 1.76 & 2.0 & 0.84 & 0.59 & 0.26 & 0.16 & 0.59 & 0.84 \\
\hline (CN1448-49-28-8)T31 & 3.35 & 0.65 & 0.08 & 2.7 & 2.65 & 1.48 & 0.56 & 0.50 & 0.19 & 1.09 & 0.81 \\
\hline (MUSG014052-51-35)T35 & 4.45 & 0.85 & 0.14 & 3.6 & 3.01 & 1.94 & 0.56 & 0.66 & 0.19 & 1.43 & 0.81 \\
\hline (MUSG014019-7-22)T16 & 4.85 & 1.26 & 0.23 & 3.59 & 3.45 & 2.47 & 0.49 & 0.97 & 0.26 & 2.00 & 0.74 \\
\hline (Vita)T38 & 5.2 & 1.7 & 0.33 & 3.5 & 5.18 & 2.97 & 0.42 & 1.31 & 0.33 & 2.56 & 0.67 \\
\hline (MUSG014065-21-13)T21 & 7.95 & 2.41 & 0.71 & 5.54 & 4.0 & 4.38 & 0.45 & 1.86 & 0.30 & 3.70 & 0.70 \\
\hline (MUSG014065-21-14)T27 & 6.0 & 2.0 & 0.44 & 4.0 & 4.65 & 3.46 & 0.42 & 1.54 & 0.33 & 3.00 & 0.67 \\
\hline (MUSG014019-7-50)T11 & 8.0 & 1.3 & 0.38 & 6.7 & 3.43 & 3.22 & 0.59 & 1.00 & 0.16 & 2.24 & 0.84 \\
\hline (Wogabolige)T34 & 5.75 & 1.1 & 0.23 & 4.65 & 3.25 & 2.51 & 0.56 & 0.85 & 0.19 & 1.85 & 0.81 \\
\hline
\end{tabular}

Yp: Yield under full irrigation Ys: Yield under stress Ȳs yield mean in stress, Ȳp non-stress conditions, STI: Stress tolerance index, TOL: Tolerance, MPI: Mean productivity index, GMP: Geometric mean productivity, SSI: Stress susceptibility index, YI: Yield index, YSI: Yield stability index, HM: Harmonic mean, and SII: Stress intensity index 
MUSG014001-3-11 and Naspot-12 genotypes had a lower value and were considered susceptible to stress, and all other genotypes were intermediate.

\section{Geometric Mean productivity (GMP)}

Genotypes with high GMP levels can be deemed drought tolerant. The highest GMP was achieved by MUSG01406521-13, closely followed by MUSG014065-21-14, indicating drought resistance, whereas lower values were reported by MUSG014001-3-11, CN1448-49-28-8, and MUSG014052-5135 , indicating drought susceptibility.

\section{Harmonic Mean (HM)}

The most suitable genotypes for HM were MUSG01406521-13 and MUSG014065-21-14, while MUSG014001-3-11 and CN1448-49-28-8 had the lowest value for these indices.

\section{Stress Intensity Index (SII)}

The SSI > 1 value suggested a higher-than-average susceptibility to drought stress. The result showed that all varieties had $\mathrm{SII}<1$ score, indicating that they are suitable and drought tolerant under stress condition.

\section{Ranking of genotypes}

Different indices designate different genotypes as drought resistant; hence identifying drought tolerant genotypes based on a single criterion does not yield clear results. To identify desirable drought tolerant genotypes, the mean rank, standard deviation of ranks, and rank sum of all indices were calculated. MUSG014065-21-13 (3.3), MUSG014065-21-14 (4.6), and MUSG014019-7-50 (5.1) had the best mean rank, rank sum, and relatively low rank sum and standard deviation of ranks when all indices were taken into account. MUSG014001-3-11 (11.4), CN1448-49-28-8 (10.0), MUSG014052-51-35 (8.4), and Naspot-12 (8.1) were thus identified as the most drought tolerant genotypes, while genotypes MUSG014001-3-11 (11.4), CN1448-49-28-8 (10.0), MUSG014052-51-35 (8.4), and closely followed by Naspot-12 (8.1) were identified as the most sensitive genotype (Table 2 ).

\section{Correlations of drought tolerance indices and storage root yield}

The correlation coefficients between Yp, Ys, and other drought tolerant criteria were used to determine the most acceptable drought tolerant criterion. Drought tolerance indicators were calculated quantitatively (Table 3). In other terms, a correlation study between two or more variables. Storage root yield and drought tolerance indices can be useful for determining which cultivars and indices are the best. The correlation between Yp and Ys was positive and significant, indicating that drought-stressed plants can be selected indirectly based on their performance in non-stressed conditions. STI $(r=0.95)$, GMP $(r=0.96), M P(r=0.63)$, YI $(r$ $=1.00)$, YSI $(r=0.99)$ and TOL $(r=0.57)$ were all substantially and positively linked with mean storage root yield under stress (Ys). On the other hand, there was a substantial and negative correlation between SSI $(r=-0.79)$ and HM $(r=-0.79)$ and Ys (Table 3). Mean stored root yield under stress (Yp) had a positive and significant connection with STI $(r=0.88)$, GMP ( $r$ $=0.92)$, YI $(r=0.77)$, SII $(r=0.83)$, and TOL $(r=0.96)$. On the other hand, there was a negative correlation between SSI ( $r=$ -0.26) and HM ( $\mathrm{r}=-0.26)$ and Yp (Table 3$)$.

\section{Discussion and conclusion}

Storage root yield of cultivars under both non-stress and stress situations were measured for computing different sensitivity and tolerance indices to examine potential stress resistance indices for screening of cultivars under drought conditions (Table 1). Under both conditions, a suitable index must have a significant correlation with grain yield (Mitra, 2001). STI, GMP, MP, YI, YSI, and TOL were all substantially and positively linked with mean storage root yield under stress (Ys). SSI and HM with Ys, on the other hand, showed a substantial and negative association. Mean storage root yield under stress (Yp) was also found to have a positive and

Table 2: Rank (R) of drought tolerance indices.

\begin{tabular}{|c|c|c|c|c|c|c|c|c|c|c|c|c|c|}
\hline \multirow[t]{2}{*}{ Genotypes } & \multirow{2}{*}{$\begin{array}{c}\text { Stress } \\
\text { Ys }\end{array}$} & \multirow{2}{*}{$\begin{array}{c}\text { Full-irrigation } \\
\qquad Y p\end{array}$} & \multicolumn{2}{|c|}{ Yield } & \multirow{2}{*}{$\begin{array}{c}\text { Tolerance } \\
\text { TOL }\end{array}$} & \multicolumn{2}{|c|}{ Productivity } & \multicolumn{3}{|c|}{ Stress } & \multirow{2}{*}{$\begin{array}{l}\text { Mean } \\
\text { HM }\end{array}$} & \multirow[t]{2}{*}{ Meadia $\pm S D$} & \multirow[t]{2}{*}{$\Sigma(\mathbf{R})$} \\
\hline & & & YI & YSI & & MPI & GMP & STI & SSI & SII & & & \\
\hline (Naspot-12) & 4 & 8 & 4 & 2 & 8 & 10 & 7 & 6 & 5 & 5 & 5 & $5.8 \pm 2.3$ & 8.1 \\
\hline (MUSG014001-3-11) & 10 & 10 & 10 & 6 & 10 & 9 & 10 & 9 & 1 & 1 & 10 & $7.8 \pm 3.6$ & 11.4 \\
\hline (CN1448-49-28-8) & 9 & 9 & 9 & 5 & 9 & 8 & 9 & 8 & 2 & 2 & 9 & $7.2 \pm 2.8$ & 10.0 \\
\hline (MUSG014052-51-35) & 8 & 7 & 8 & 5 & 5 & 7 & 8 & 7 & 2 & 2 & 8 & $6.1 \pm 2.3$ & 8.4 \\
\hline (MUSG014019-7-22) & 6 & 6 & 6 & 4 & 6 & 4 & 6 & 5 & 3 & 3 & 6 & $5.0 \pm 1.3$ & 6.3 \\
\hline (Vita) & 3 & 5 & 3 & 1 & 7 & 1 & 4 & 4 & 6 & 6 & 3 & $3.9 \pm 2.0$ & 5.9 \\
\hline (MUSG014065-21-13) & 1 & 2 & 1 & 3 & 2 & 3 & 1 & 1 & 4 & 4 & 1 & $2.1 \pm 1.2$ & 3.3 \\
\hline (MUSG014065-21-14) & 2 & 3 & 2 & 1 & 4 & 2 & 2 & 2 & 6 & 6 & 2 & $2.9 \pm 1.7$ & 4.6 \\
\hline (MUSG014019-7-50) & 5 & 1 & 5 & 6 & 1 & 5 & 3 & 3 & 1 & 1 & 4 & $3.2 \pm 1.9$ & 5.1 \\
\hline (Wogabolige) & 7 & 4 & 7 & 5 & 3 & 6 & 5 & 5 & 2 & 2 & 7 & $4.8 \pm 1.9$ & 6.7 \\
\hline
\end{tabular}

Yp: Yield under full irrigation Ys: Yield under stress Ȳs yield mean in stress, Ȳp Yield mean in full irrigation conditions, STI: Stress Tolerance Index, TOL: Tolerance, MPI: Mean Productivity Index, GMP: Geometric Mean Productivity, SSI: Stress Susceptibility Index, YI: Yield Index, YSI: Yield Stability Index; HM: Harmonic Mean, and SII: Stress intensity index 
Table 3: Correlation coefficients between storage root yields and drought tolerance indices.

\begin{tabular}{|c|c|c|c|c|c|c|c|c|c|c|c|}
\hline & $Y p$ & Ys & STI & TOL & MP & GMP & SSI & YI & YSI & HM & SII \\
\hline$Y p$ & 1 & & & & & & & & & & \\
\hline Ys & $0.77^{\star *}$ & 1 & & & & & & & & & \\
\hline STI & $0.88^{* *}$ & $0.95^{* *}$ & 1 & & & & & & & & \\
\hline TOL & $0.96^{* *}$ & $0.57^{\star}$ & $0.73^{* *}$ & 1 & & & & & & & \\
\hline MP & 0.54 & $0.63^{*}$ & $0.59^{*}$ & 0.42 & 1 & & & & & & \\
\hline GMP & $0.92^{* *}$ & $0.96^{* *}$ & $0.97^{\text {** }}$ & $0.77^{\star *}$ & $0.63^{*}$ & 1 & & & & & \\
\hline SSI & -0.26 & $-0.79^{* *}$ & $-0.56^{*}$ & 0.01 & -0.44 & $-0.61^{*}$ & 1 & & & & \\
\hline YI & $0.77^{\star \star}$ & $1.00^{* *}$ & $0.95^{* *}$ & $0.57^{*}$ & $0.63^{*}$ & $0.96^{\text {** }}$ & $-0.79^{* *}$ & 1 & & & \\
\hline YSI & 0.26 & $0.79^{* *}$ & $0.56^{*}$ & -0.01 & 0.44 & $0.61^{*}$ & $-1.00^{\star *}$ & $0.79^{* *}$ & 1 & & \\
\hline $\mathrm{HM}$ & -0.26 & $-0.79^{* *}$ & $-0.56^{\star}$ & 0.01 & -0.44 & $-0.61^{*}$ & $1.00^{\star *}$ & $-0.79^{* *}$ & $-1.00^{* *}$ & 1 & \\
\hline SII & $0.83^{* *}$ & $0.99^{* *}$ & $0.96^{* *}$ & $0.64^{*}$ & $0.64^{*}$ & $0.98^{\star \star}$ & $-0.73^{\star *}$ & $0.99^{* *}$ & $0.73^{* *}$ & $-0.73^{* *}$ & \\
\hline
\end{tabular}

**, * = significant at 0.01 and 0.05 respectively, NS = Non-Significant, Yp: Yield under full irrigation Ys: Yield under stress Ȳs yield mean in stress, Ȳp non-stress conditions, STI: Stress Tolerance Index, TOL: Tolerance, MPI: Mean Productivity Index, GMP: Geometric Mean Productivity, SSI: Stress Susceptibility Index, YI: Yield Index, YSI: Yield Stability Index, HM: Harmonic Mean and SII: Stress Intensity Index

significant relationship with STI, GMP, YI, SII, and TOL. On the other hand, there was a negative association between SSI and HM and Yp. This means that selecting for greater STI, GMP, MP, YI, YSI, and TOL values allows for high yield selection under drought stress. As a result, the STI, GMP, MP, YI, and TOL indices can be used to distinguish genotypes with greater drought resistance from those with higher storage root yield. Naghavi, et al. (2013) found that STI, GMP, MP, YI, YSI, and TOL were all positively linked with Ys in maize, which is consistent with this finding. Storage root yield demonstrated a significant positive correlation with STI, GMP, SII, YI, STI, and TOL under both water regime circumstances, indicating that these indices might be used to select genotypes with high grain production under drought stressed and non-stressed conditions. The findings support the findings of Yasir, et al. (2013), who found a positive correlation between STI, GMP, MP, and YI. This study's findings matched those of Farshadfar, et al. [21] in bread wheat, where all of these indicators were found to be strongly and positively correlated. Storage root yield was significantly correlated with STI, GMP, MP, YI, YSI, and TOL in both moisture regimes, indicating that these indices might be used to select genotypes with high storage root production under drought stressed and non-stressed circumstances. The current findings were consistent with those of Ashraf, et al. (2015) in bread wheat and Yousefi (2015) in barely, both of whom found a significant and positive correlation between grain yield in Ys and Yp circumstances with STI, MP, GMP, YI, HM, and DRI in Ys and Yp conditions. High correlations of indices with both Ys and Yp are best for identifying stress tolerant genotypes, which agrees with Farshadfar, et al. findings (2011) The most effective indices for selecting drought tolerant cultivars, according to Khalilzade and Karbalai-Khiavi (2002) and Farshadfar, et al. [21], is an indicator that has a relatively high correlation with grain yield in both moisture stress and non-stress conditions. As a result of the correlation between stress tolerance and yield in both situations, the most appropriate indices for screening drought tolerant genotypes were discovered. Fernandez [14] further demonstrated that indices with a relatively high connection with grain production in both environmental conditions are the most effective indicators for selecting drought-tolerant cultivars (i.e. genotypes with consistence superiority under both moisture conditions). The findings of correlation experiments in durum wheat were generally consistent with those of Golabadi, et al. (2006).

According to the findings of this study, STI, MP, GMP, and YI are appropriate indices for identifying genotypes that produce greater yields under both stress and non-stress environments (drought tolerant genotypes). MUSG014065-21-13 (3.3), MUSG014065-21-14 (4.6), and Vita genotypes were identified as the most drought tolerant using ranking of genotypes based on rank, rank some, and standard deviation. Drought tolerance indices GMP, STI, MP, TOL YI, and YSI, according to correlation analysis are superior indices for identifying genotypes that yield well under stressed and irrigated situations. GMP and YI were also discovered to be more relevant indicators for distinguishing tolerant genotypes that are stable in a variety of environments and provide high storage yield under stress.

\section{Acknowledgments}

I would like to thank the Hawassa Agricultural Research Center for preparing the sweet potato genotypes that were used in the experiments and Intra-Africa academy project.

\section{References}

1. Pinter PJ, Zipoli G, Reginato RJ, Jackson RD, Idso SB, et al. (1990) Canopy temperature as an indicator of differential water use and yield performance among wheat cultivars. Agricultural Water Management 18: 35-48. Link: https://bit.ly/2XSCMUf

2. Singh BD (2002) Plant Breeding: Principles and Methods. Kalyani Publishers, New Delhi-Ludhiana. Link: https://bit.ly/2XMNMCp

3. Keneni $\mathrm{G}$ (2007) Concerns on mismatches between environments of selection and production of crop varieties in Ethiopia. East African Journal of Sciences 1: 93-103. Links: https://bit.ly/3kgV0Gx

4. Blum A (2011) Drought resistance: is it really a complex trait? Functional Plant Biology 38: 753-757. Link: https://bit.ly/3DgF53M 
5. Araus JL, Cairns JE (2014) Field high-throughput phenotyping: the new crop breeding frontier.TrendsinPlantScience19(1):52-61.Link: https://bit.ly/3japDhf

6. Raman A, Verulka S, Manda N, Variar V, Shukla V, et al. (2012) Drought yield index to select high yielding rice lines under different drought stress severities. Rice 5: 31-43. Link: https://bit.ly/3muenhY

7. Mohammadi R (2016) Efficiency of yield-based drought tolerance indices to identify tolerant genotypes in durum wheat. Euphytica 211: 71-89. Link: https://bit.ly/3jbWBOT

8. Mitra J (2001) Genetics and genetic improvement of drought resistance in crop plants. Current Sci 80: 758-762. Link: https://bit.ly/3gt8DRQ

9. Hall $A E$ (1993) Is dehydration tolerance relevant to genotypic differences in leaf senescence and crop adaptation to dry environments? In: Close TJ, \& E. A. Bray (Eds) Plant Responses to cellular Dehydration during environmental stress (pp. 1-10). Link: https://bit.ly/3DeTT2P

10. Blum A (1988) Plant Breeding for Stress environments.CRC Press Florida. Link: https://bit.ly/3ycWZQU

11. Ramirez P, Kelly JD (1998) Traits related to drought resistance in common bean. Euphytica 99: 127-136. Link: https://bit.ly/2WcC8k3

12. Fischer RA, Rees D, Sayre KD, Lu ZM, Condon AG, et al. (1998) Wheat yield progress associated with higher stomatal conductance and photosynthetic rate, and cooler Canopies. Crope Science 38: 1467-1475. Link: https://bit.ly/2UG9PcM

13. Rosielle AA, Hamblin J (1981) Theoretical aspects of selection for yield in stress and non-stress environments. Crop Science 21: 943-946. Link: https://bit.ly/3mrlgiV
14. Fernandez GCJ (1992) Effective selection criteria for assessing plant stress tolerance. Proceedings of the International Symposium on Adaptation of Vegetables and other Food Crops in Temperature and Water Stress, Chapter 25, Taiwan. Link: https://bit.ly/3AYgqPo

15. Fischer RA, Maurer R (1978) Drought resistance in spring wheat cultivars. I. Grain yield responses. Australian Journal of Agricultural Research 29: 897912. Link: https://bit.ly/2Wnn56s

16. Clarke JM, DePauw RM, Townley Smith TF (1992) Evaluation of methods for quantification of drought tolerance in wheat. Crope Science 32: 423-428. Link: https://bit.ly/3mtdoyE

17. Guttieri MJ, Stark JC, Brien K, Souza E (2001) Relative sensitivity of spring wheat grain yield and quality parameters to moisture deficit. Crop Sci 41: 327 335. Link: https://bit.ly/3zd3m8p

18. Gavuzzi P, Rizza F, Palumbo M, Campaline RG, Ricciardi GL, et al. (1997) Evaluation of field and laboratory predictors of drought and heat tolerance in winter cereals. Plant Sci 77: 523-531. Link: https://bit.ly/3mwuUls

19. Bouslama M, Schapaugh WT (1984) Stress tolerance in soybean. Part 1 evaluation of three screening techniques for heat and drought tolerance. Crope Science 24: 933-937. Link: https://bit.ly/3B8FfYQ

20. Fekadu G, Hussein S, Mark L (2018) Combining Ability, Heterosis and Heritability of Storage Root Dry Matter, Beta-Carotene and Yield-related Traits in Sweetpotato. HortScience 53: 167-175. Link: https://bit.ly/30n2Xk0

21. Farshadfar E, Mahmodi N, Yaghotipoor A (2011) AMMI stability value and simultaneous estimation of yield and yield stability in bread wheat (Triticum aestivum L.) Australian Journal of Crop Science 5: 1837-1844. Link: https://bit.ly/3mudxSm

Copyright: () 2021 Gitore SA, et al. This is an open-access article distributed under the terms of the Creative Commons Attribution License, which permits unrestricted use, distribution, and reproduction in any medium, provided the original author and source are credited.

Citation: Gitore SA, Danga B, Henga S, Gurmu F (2021) Evaluating Drought tolerance indices for selection of drought tolerant Orange Fleshed Sweet Potato (OFSP) genotypes in Ethiopia. J Agric Sc Food Technol 7(2): 249-254. DOI: https://dx.doi.org/10.17352/2455-815X.000115 